\title{
Peran Orangtua dalam Melatih Keterampilan Sosial pada Remaja dengan Autisme
}

\author{
Maharani Dinda Kallista \\ Fakultas Psikologi Universitas Surabaya \\ dinda.kallista@gmail.com \\ Lena N. Panjaitan \\ Fakultas Psikologi Universitas Surabaya \\ lenapanjaitan66@gmail.com \\ Aniva Kartika \\ Fakultas Psikologi Universitas Surabaya \\ anivakartika@gmail.com
}

\begin{abstract}
Adolesscent with Autism Spectrum Disorder (ASD) tend to be ostracized and bullied in school because they have fewer social skills. Though social skills can be improved, even though ASD teens will have certain challenges. Therefore the role of parents is very important in improving their social skills. This research was conducted to see how the description of social skills possessed by ASD adolescents, viewed from an internal process consisting of three aspects namely emotional awareness and understanding, a theory of mind, and problem-solving and how the role of parents in training social skills in them. Participants in this study were two mothers from mild ASD adolescents. Methods of data collection through interviews, open questionnaires, and four measuring instruments (Karolinska Directed Emotional Face test, Faux Pas Stories Test, Problem Solving Questionnaire, and Recognizing and Responding to a Problem Situation Assessment). The results of this study indicate that the role of parents in practicing social skills in ASD adolescents has not shown optimal results, as evidenced by the lack of social skills possessed by ASD adolescents and the social problems they face in school.
\end{abstract}

Keywords: social skills; emotional awareness; and understanding; a theory of mind; problem-solving; parental role; autism

\begin{abstract}
Abstrak
Remaja dengan Autism Spectrum Disorder (ASD) cenderung dikucilkan dan dibully di sekolah karena memiliki keterampilan sosial yang kurang. Padahal keterampilan sosial dapat ditingkatkan, walaupun pada remaja ASD akan memiliki tantangan tertentu. Maka dari itu peran orangtua sangatlah penting dalam meningkatkan keterampilan sosial mereka. Penelitian ini dilakukan untuk
\end{abstract}


melihat bagaimana gambaran keterampilan sosial yang dimiliki oleh remaja ASD, ditinjau dari proses internal yang terdiri dari tiga aspek yakni kesadaran dan pemahaman emosi, theory of mind, dan problem solving serta bagaimana peran orangtua dalam melatih keterampilan sosial pada mereka. Partisipan dalam penelitian ini adalah dua orang ibu dari remaja ASD kategori ringan. Metode pengumpulan data melalui wawancara, kuesioner terbuka, dan empat alat ukur (Karolinska Directed Emotional Face test, Faux Pas Stories Test, Problem Solving Questionnaire, dan Recognizing and Responding to a Problem Situation Assessment). Hasil dari penelitian ini menunjukkan bahwa peran orangtua dalam melatih keterampilan sosial pada remaja ASD belum menunjukkan hasil yang optimal, terbukti dengan masih kurangnya keterampilan sosial yang dimiliki oleh remaja ASD dan permasalahan sosial yang mereka hadapi di sekolah.

Kata kunci: keterampilan sosial; kesadaran dan pemahaman emosi; theory of mind; problem solving; peran orangtua; autisme

\section{Pendahuluan}

Individu dengan Autism Spectrum Disorder (ASD) memiliki kelemahan dalam interaksi sosial dan komunikasi, dan kadang memiliki masalah perilaku seperti self-injuries, tantrum, agresi, hiperaktif, kecemasan, atau depresi (American Psychiatric Association, 2000). Hal ini menyebabkan individu dengan ASD kurang memiliki pemahaman perilaku untuk berinteraksi dengan orang lain, seperti kurangnya orientasi terhadap stimulus, kontak mata yang kurang, tidak ada atau kurangnya inisiasi dalam interaksi sosial, kesulitan menginterpretasi isyarat sosial dalam bentuk verbal maupun non verbal, respon emosional yang kurang pantas, dan kurang empati terhadap masalah atau emosi orang lain (Murray dalam Dekker, 2014). Kekurangan dan kesulitan tersebut menandakan bahwa individu dengan ASD memiliki keterampilan sosial yang kurang.

Keterampilan sosial merupakan suatu perilaku belajar sosial yang membuat seseorang mampu berinteraksi dengan orang lain (Elliot dalam Little, 2017). Keterampilan sosial bukanlah hal yang terbentuk semenjak individu lahir, namun merupakan proses belajar seumur hidup, masing-masing individu memiliki kesempatan untuk mengembangkan keterampilan sosialnya, begitu pula dengan individu ASD. Keterbatasan kemampuan komunikasi sosial yang merupakan masalah inti individu ASD, bukan berarti bahwa tidak akan ada perkembangan sama sekali di area ini (White, 2007), namun proses belajar dan implementasi 
perilaku untuk melatih interaksi sosial akan menjadi lebih berat, lambat, dan sedikit sulit dibandingkan dengan individu dengan perkembangan normal (Laugeson dalam Dekker, 2014).

Keterampilan sosial dalam penelitian ini diartikan sebagai kemampuan yang diharapkan dapat membuat individu berinteraksi dengan orang lain, memiliki perilaku yang dianggap 'normal', dapat diterima, dan diharapkan dalam situasi sosial tertentu, dan sesuai dengan norma sosial yang ada di masyarakat (Patrick, 2008). Patrick (2008) menjelaskan bahwa keterampilan sosial memiliki tiga elemen yakni social intake, internal process, dan social output. Pada penelitian ini, fokus kepada internal process dimana elemen ini terdiri dari (1)Aspek kesadaran dan pemahaman emosi, baik memahami emosi yang ditunjukkan orang lain maupun dirinya sendiri; (2)Theory of mind, kemampuan untuk mengakui bahwa pikiran dan keyakinan orang berbeda satu sama lain, membuat kesimpulan tentang apa yang orang lain pikirkan dan rasakan, serta untuk memprediksi perilaku yang sesuai; (3)Problem solving dalam kehidupan sosial (interpersonal), proses kognitif-interpersonal yang ditujukan untuk mengidentifikasi atau menemukan resolusi konflik yang dapat diterima atu memuaskan masing-masing pihak (Solomon, 2004).

Kurangnya keterampilan sosial pada remaja ASD, dapat diketahui melalui indikator yang dipaparkan oleh Weiss dan Harris (2001), antara lain kurangnya perhatian terhadap stimulus sosial, kontak mata yang canggung (inadekuat), mengalami masalah dalam menginisiasi interaksi sosial, kesulitan menginterpretasikan isyarat sosial, baik verbal maupun non-verbal, respon emosional yang belum tepat, kurangnya empati terhadap kesulitan orang lain. Selain itu, Gutstein dan Whitney (2002) juga menambahkan bahwa pada remaja ASD juga ditemukan kesulitan untuk berbagi pengalaman afeksi dan memahami perspektif orang lain.

Kurangnya keterampilan sosial yang dimiliki oleh individu ASD tidak berarti membuat mereka tidak ingin menjalin relasi. Individu dengan ASD sama seperti kebanyakan individu lain yang ingin berperan aktif dalam interaksi sosial, tapi mereka tidak berperilaku sebagaimana mestinya untuk menghasilkan interaksi 
sosial yang mengalir/lancar dengan teman sebayanya. Hal ini dikarenakan mereka memiliki kesulitan untuk berbagi pengalaman afeksi atau memahami cara pandang orang lain. Pada beberapa penelitian, guru dan orangtua melaporkan adanya perilaku kurang kooperatif, asertif, dan kontrol diri pada individu ASD yang meningkatkan resiko penolakan dari teman dan isolasi sosial terhadap individu dengan ASD (Murray dalam Dekker, 2014).

Berbagai intervensi telah dilakukan untuk meningkatkan keterampilan sosial individu ASD, seperti Social Skills Group Training (SSGT) oleh Olsson (2017), Social Adjustment Enhancement Intervention oleh Solomon (2004). Dari beberapa penelitian tersebut, terdapat tugas-tugas yang diberikan kepada orangtua sehingga dapat membantu proses dan kelancaran intervensi. Laugeson (dalam Karst, 2014) menyatakan bahwa peran orangtua sebagai 'social coaching' menjadi penguat dan mampu membuat keterampilan sosial yang dimiliki oleh individu ASD berlaku lama dibandingkan dengan yang tidak didampingi oleh orangtua.

Pada kenyataan yang ditemukan peneliti di lapangan terhadap dua remaja ASD sebagai anak dari partisipan penelitian, peneliti menemukan bahwa orangtua $\mathrm{P}$ mengaku bahwa ibu hampir tidak pernah mendampingi $\mathrm{P}$ untuk belajar ataupun melatih kemampuan sosialnya, ibu banyak menyerahkan penanganan permasalahan sosial kepada terapis (dulu) dan guru sekolahnya. Hal ini dikarenakan ibu merasa tidak tahu bagaimana cara menangani dan menilai P dapat berkembang sendiri di luar sana. Orangtua, dalam hal ini ibu, jarang sekali menanyakan bagaimana teman-temannya di sekolah, siapa teman baik P, atau interaksi $\mathrm{P}$ dengan teman-temannya. Ketika $\mathrm{P}$ menemui masalah mengenai bullying di sekolah, Ibu hanya menyarankan $\mathrm{P}$ agar diam saja dan membiarkan teman-temannya berbuat seperti itu, untuk kemudian nanti dilaporkan kepada guru Bimbingan dan Konseling di sekolah.

Sedangkan pada Z, orangtua terlihat kurang sekali terlibat dalam permasalahan sosial yang dihadapi oleh subjek. Respon orangtua yang diberikan saat $\mathrm{Z}$ menyampaikan kesulitannya dengan teman di sekolahnya, seringkali direspon hanya dengan kalimat, "Ah..Cuma gitu aja..nggak serius lah itu. Gapapa, 
yang penting kamu tetep baik sama dia". Akan tetapi orangtua berusaha memberikan dorongan agar $\mathrm{Z}$ lebih aktif dalam kegiatan sosial sehari-hari, tanpa pembekalan keterampilan sosial yang tepat. Akibatnya seringkali $\mathrm{Z}$ hanya berbicara mengenai hal-hal yang disukainya saja dan tidak menghiraukan isi pembicaraan orang lain.

Tujuan dari penelitian ini adalah untuk mengetahui gambaran keterampilan sosial yang dimiliki oleh remaja ASD, ditinjau dari tiga aspek yaitu kesadaran emosi, theory of mind, dan kemampuan problem solving, serta mengetahui penanganan yang telah dilakukan oleh orangtua, khususnya ibu, untuk melatih keterampilan sosial pada remaja ASD di rumah. Sedangkan manfaat dari penelitian ini antara lain memberikan gambaran baik kepada orangtua dengan remaja ASD, maupun para praktisi yang bergelut di dunia ASD mengenai keterampilan sosial yang dimiliki oleh remaja ASD, khususnya yang terkait dengan internal process dalam diri mereka. Selain itu, juga dapat memberikan gambaran bagaimana seharusnya pendampingan yang tepat bagi orangtua untuk melatih keterampilan sosial remaja ASD di rumah.

\section{Metode}

Metode yang digunakan dalam penelitian ini adalah metode penelitian deskriptif kualitatif. Penelitian deskriptif kualitatif ini ditujukan untuk mendeskripsikan dan menggambarkan fenomena-fenomena yang ada, baik bersifat alamiah maupun rekayasa manusia, yang lebih memperhatikan karakteristik, kualitas, keterkaitan antar kegiatan (Sukmadinata, 2011).

Subjek dari penelitian ini diambil menggunakan teknik purposive sampling, memilih partisipan berdasarkan kriteria tertentu. Kriteria subjek yang digunakan dalam penelitian ini adalah dua orang ibu yang memiliki anak terdiagnosa ASD kategori ringan, berusia remaja (11-19 tahun); berpendidikan minimal SLTA; dan tidak bekerja atau menjadi ibu rumah tangga yang mendampingi anaknya di rumah. 
Tabel 1. Identitas Partisipan

\begin{tabular}{ccccc}
\hline & Partisipan 1 & Anak* & Partisipan 2 & Anak* \\
\hline Nama (inisial) & DW & P & YN & Z \\
Jenis Kelamin & Perempuan & Laki-laki & Perempuan & Laki-laki \\
Tempat/tanggal & Probolinggo, 8 & Probolinggo, 9 & Madiun, 1 & Probolinggo, 1 \\
lahir & Mei 1975 & Juli 2003 & Agustus 1976 & September 2005 \\
Pendidikan & SLTA & SMP kelas IX & SLTA & SMP kelas VIII \\
Pekerjaan & Ibu rumah tangga & - & Ibu rumah tangga & - \\
\hline *) anak dari partisipan yang terdiagnosa ASD kategori ringan & \multicolumn{3}{c}{}
\end{tabular}

*) anak dari partisipan yang terdiagnosa ASD kategori ringan

Peneliti kemudian melanjutkan dengan proses asesmen kepada subjek. Proses asesmen dilakukan dengan menggunakan metode wawancara terstruktur dan pemberian kuesioner terbuka. Wawancara terstruktur dilakukan dengan tujuan untuk menggali data mengenai keterampilan sosial yang dimiliki oleh anak dari partisipan serta bagaimana cara partisipan mengajarkan keterampilan sosial kepada mereka di rumah. Sedangkan kuesioner terbuka diberikan untuk menggali informasi dan memancing partisipan penelitian melakukan self-evaluation terhadap perannya selama ini dalam melatih tiga aspek dari keterampilan sosial, yakni kesadaran dan pemahaman emosi, theory of mind, dan kemampuan problem solving pada remaja dengan ASD. Selain wawancara dan kuesioner terbuka, peneliti juga menggunakan alat ukur yang akan diberikan kepada remaja ASD untuk mengetahui gambaran keterampilan sosial yang dimilikinya, sebagai berikut:

1. Karolinska Directed Emotional Faces (KDEF) untuk mengetahui kemampuan remaja ASD dalam emotional awareness yang berkaitan dengan ekspresi emosi wajah. Kepada mereka akan ditunjukkan berbagai macam gambar ekspresi wajah dari orang yang berbeda-beda. Tes ini meminta subjek untuk memilih salah satu ekspresi wajah dari enam emosi yaitu marah, sedih, takut, kaget, jijik, senang dan satu ekspresi netral (tanpa emosi). Setiap ekspresi akan diwakilkan oleh 20 gambar dari orang yang berbeda (total 140 gambar) dan diberikan secara acak.

2. Faux Pas Stories Task untuk mengetahui kemampuan theory of mind yang dimiliki oleh remaja ASD. Faux Pas Stories Task terdiri dari dua subtes, tes faux pas yang terdiri dari sepuluh cerita berisi kesalahan palsu (faux pas) dan sepuluh cerita kontrol dimana di dalamnya tidak terdapat kesalahan palsu (faux 
pas). Cerita diberikan secara acak dan setelah selesai dibacakan satu cerita, peneliti memberikan empat pertanyaan yang terdiri dari pertanyaan deteksi, identifikasi, komprehensi, dan false belief. Satu skor benar diberikan apabila subjek dapat menjawab keempat pertanyaan dengan benar, pada cerita faux pas jawaban dari pertanyaan deteksi selalu ada, sedangkan pada cerita kontrol jawaban dari pertanyaan deteksi selalu tidak ada.

3. Problem Solving Questionnaire (PSQ) dan Recognizing and Responding to a Problem Situation Assessment (RRPS) untuk mengetahui pemahaman remaja ASD mengenai problem solving dan sejauh mana kemampuan mereka untuk dapat menyelesaikan masalah. PSQ terdiri dari delapan pertanyaan. Sedangkan RRPS terdiri dari lima cerita pendek, dimana tiga cerita menampilkan permasalahan sedangkan dua lainnya tidak. Setiap dibacakan satu cerita, peneliti akan memberikan enam pertanyaan yang terkait dengan cerita tersebut.

\section{Hasil dan Pembahasan}

Dari hasil asesmen yang telah dilakukan terhadap keterampilan sosial yang dimiliki oleh remaja ASD, didapatkan hasil sebagai berikut:

1. Kesadaran dan pemahaman emosi

Berdasarkan data yang telah diperoleh dari alat ukur pengenalan ekspresi emosi wajah, P (anak dari DW) mendapatkan skor 75 dan Z (anak dari YN) mendapatkan skor 106 dari 140 soal.

Tabel 2. Sebaran Skor KDEF

\begin{tabular}{ccc}
\hline Ekspresi & P & Z \\
\hline Senang & 20 & 20 \\
\hline Sedih & 3 & 17 \\
\hline Marah & 1 & 11 \\
\hline Netral & 18 & 19 \\
\hline Takut & 0 & 8 \\
\hline Jijik & 17 & 17 \\
\hline Kaget & 18 & 14 \\
\hline
\end{tabular}

Hasil tes face recognition $\mathrm{KDEF}$, menunjukkan bahwa $\mathrm{P}$ dan $\mathrm{Z}$ dapat menjawab dengan benar semua ekspresi senang. Akan tetapi $\mathrm{P}$ mengalami kesulitan pada ekspresi sedih (3/20), marah (1/20), takut (0/20). Sedangkan Z 
banyak melakukan kesalahan pada ekspresi marah (11/20), dan takut (8/20). Hal ini dikarenakan baik $\mathrm{P}$ maupun $\mathrm{Z}$ kurang menjalin kontak mata dengan lawan bicara. Mereka cenderung menghindar, menunduk, atau melihat ke arah lain saat berbicara. $\mathrm{P}$ juga cenderung untuk melihat wajah bagian bawah saja (hidung ke bawah). Hal ini identik dengan karakteristik individu ASD dimana mereka cenderung untuk tidak melihat pada area mata orang lain melainkan lebih senang untuk mendapatkan informasi dari area mulut (Tanaka, 2016). Kecenderungan mereka untuk melihat area mulut, memudahkan mereka untuk mengenali ekspresi senang dan jijik karena dapat diidentifikasi hanya melalui area mulut saja. Sedangkan ekspresi marah, takut, dan sedih ditunjukkan secara kuat melalui area mata (Wegrzyn, 2017).

Selain itu, dapat dilihat pula bahwa skor yang diperoleh $\mathrm{Z}$ jauh lebih banyak daripada P. Hal ini karena stimulasi yang pernah diberikan oleh orangtua berbeda. Pada kasus Z, ibu pernah melatihnya untuk mengamati dan mengenal ekspresi wajah orang lain pada saat $\mathrm{Z}$ masih kecil. Sedangkan ibu P mengaku sama sekali tidak pernah menstimulasi P untuk mengenal emosi, walaupun ibu mengetahui bahwa kesulitan P untuk mengenal ekspresi wajah karena ia tidak pernah menatap wajah lawan bicaranya. Akan tetapi ibu $\mathrm{P}$ hanya sekedar mengingatkan untuk menatap wajah lawan bicara ketika sedang bercakap-cakap.

Kurangnya kemampuan kesadaran dan pemahaman emosi ini menyebabkan remaja dengan ASD kesulitan untuk memahami emosi yang ditampilkan oleh lawan bicaranya, sehingga mereka akan kesulitan untuk melakukan aksi timbal-balik dalam berkomunikasi. Akibatnya remaja dengan ASD mengalami resiko dikucilkan dari lingkungan sosial, penolakan dari teman sebaya, dan bullying (Frith \& Frith dalam Berggren, 2017). Hal ini pun dialami oleh $\mathrm{P}$ dan $\mathrm{Z}$, di lingkungan sekolah mereka seringkali di-bully oleh teman-teman dan jarang diajak bermain bersama.

\section{Theory of Mind}

Hasil tes identifikasi adanya faux pas (seseorang mengatakan tanpa mempertimbangkan apakah orang lain mampu mendengar atau mengetahuinya, 
dan biasanya memiliki dampak negatif kepada pendengar) dapat dilihat pada tabel berikut:

Tabel 3. Skor Cerita Faux Pas

\begin{tabular}{|c|c|c|c|c|c|c|c|c|c|c|}
\hline \multirow{2}{*}{$\begin{array}{c}\text { No } \\
\text { Cerita }\end{array}$} & \multicolumn{5}{|c|}{$P$} & \multicolumn{5}{|c|}{$\mathrm{Z}$} \\
\hline & PD & PI & PK & FB & Skor & PD & PI & PK & FB & Skor \\
\hline 1 & $\mathrm{O}$ & $\mathrm{X}$ & O & $\mathrm{X}$ & 0 & $\mathrm{O}$ & $\mathrm{X}$ & $\mathrm{O}$ & O & 0 \\
\hline 2 & $\mathrm{O}$ & $\mathrm{O}$ & $\mathrm{O}$ & $\mathrm{X}$ & 0 & $\mathrm{O}$ & $\mathrm{x}$ & $\mathrm{O}$ & $\mathrm{X}$ & 0 \\
\hline 3 & 0 & $\mathrm{O}$ & o & $\mathrm{X}$ & 0 & O & $\mathrm{X}$ & o & o & 0 \\
\hline 4 & 0 & $\mathrm{o}$ & $\mathrm{O}$ & $\mathrm{x}$ & 0 & 0 & $\mathrm{O}$ & $\mathrm{O}$ & $\mathrm{x}$ & 0 \\
\hline 5 & $\mathrm{O}$ & $\mathrm{x}$ & $\mathrm{O}$ & $\mathrm{x}$ & 0 & $\mathrm{O}$ & $\mathrm{x}$ & $\mathrm{O}$ & $\mathrm{x}$ & 0 \\
\hline 6 & $\mathrm{O}$ & $\mathrm{O}$ & $\mathrm{O}$ & $\mathrm{x}$ & 0 & $\mathrm{O}$ & $\mathrm{x}$ & $\mathrm{O}$ & $\mathrm{x}$ & 0 \\
\hline 7 & 0 & 0 & $\mathrm{O}$ & 0 & 1 & $\mathrm{O}$ & $\mathrm{O}$ & $\mathrm{O}$ & $\mathrm{O}$ & 1 \\
\hline 8 & $\mathrm{O}$ & $\mathrm{X}$ & $\mathrm{O}$ & $\mathrm{X}$ & 0 & $\mathrm{x}$ & $\mathrm{X}$ & $\mathrm{O}$ & $\mathrm{O}$ & 0 \\
\hline 9 & 0 & 0 & 0 & $\mathrm{O}$ & 1 & 0 & $\mathrm{O}$ & 0 & $\mathrm{x}$ & 0 \\
\hline 10 & $\mathrm{O}$ & $\mathrm{x}$ & $\mathrm{O}$ & $\mathrm{X}$ & 0 & $\mathrm{O}$ & $\mathrm{x}$ & $\mathrm{O}$ & $\mathrm{X}$ & 0 \\
\hline \multicolumn{5}{|c|}{ Total Skor } & 2 & \multicolumn{4}{|c|}{ Total Skor } & 1 \\
\hline
\end{tabular}

PD: Pertanyaan Deteksi; PI: Pertanyaan Identifikasi; PK: Pertanyaan Komprehensi; FB: False-Belief; o: jawaban benar; x:jawaban salah

Tabel 4. Skor Cerita Kontrol

\begin{tabular}{|c|c|c|c|c|c|c|c|c|c|c|}
\hline \multirow{2}{*}{$\begin{array}{c}\text { No } \\
\text { Cerita }\end{array}$} & \multicolumn{5}{|c|}{$\mathrm{P}$} & \multicolumn{5}{|c|}{$\mathrm{Z}$} \\
\hline & PD & PI & PK & FB & Skor & PD & PI & PK & FB & Skor \\
\hline 1 & $\mathrm{x}$ & $\mathrm{X}$ & 0 & $\mathrm{x}$ & 0 & $\mathrm{X}$ & $\mathrm{X}$ & 0 & 0 & 0 \\
\hline 2 & $\bar{x}$ & $\mathrm{X}$ & $\mathrm{O}$ & $\mathrm{O}$ & 0 & $\mathrm{X}$ & $\mathrm{X}$ & 0 & $\mathrm{O}$ & 0 \\
\hline 3 & $\mathrm{X}$ & $\mathrm{X}$ & O & $\mathrm{x}$ & 0 & $\mathrm{X}$ & $\mathrm{X}$ & 0 & O & 0 \\
\hline 4 & $\mathrm{X}$ & $\mathrm{X}$ & 0 & $\mathrm{x}$ & 0 & 0 & 0 & 0 & $\mathrm{X}$ & 0 \\
\hline 5 & $\mathrm{X}$ & $\mathrm{X}$ & $\mathrm{O}$ & $\mathrm{O}$ & 0 & $\mathrm{O}$ & $\mathrm{O}$ & $\mathrm{O}$ & $\mathrm{X}$ & 0 \\
\hline 6 & $\mathrm{X}$ & $\mathrm{X}$ & 0 & $\mathrm{X}$ & 0 & $\mathrm{X}$ & $\mathrm{X}$ & 0 & $\mathrm{X}$ & 0 \\
\hline 7 & $\mathrm{X}$ & $\mathrm{X}$ & 0 & 0 & 0 & $\mathrm{X}$ & $\mathrm{X}$ & 0 & $\mathrm{X}$ & 0 \\
\hline 8 & $\mathrm{X}$ & $\bar{X}$ & 0 & $\mathrm{X}$ & 0 & $\bar{x}$ & $\mathrm{X}$ & 0 & $\bar{x}$ & 0 \\
\hline 9 & $\mathrm{X}$ & $\mathrm{X}$ & $\mathrm{O}$ & $\mathrm{x}$ & 0 & $\mathrm{O}$ & 0 & 0 & $\mathrm{X}$ & 0 \\
\hline 10 & $\mathrm{X}$ & $\mathrm{x}$ & 0 & $\mathrm{X}$ & 0 & $\mathrm{X}$ & $\mathrm{X}$ & 0 & $\mathrm{X}$ & 0 \\
\hline \multicolumn{5}{|c|}{ Total Skor } & 0 & \multicolumn{4}{|c|}{ Total Skor } & 0 \\
\hline
\end{tabular}

PD: Pertanyaan Deteksi; PI: Pertanyaan Identifikasi; PK: Pertanyaan Komprehensi; FB: False-Belief; o: jawaban benar; x:jawaban salah

Dari kedua tabel di atas, dapat dilihat bahwa kedua subjek secara keseluruhan mampu mendeteksi kalimat yang seharusnya tidak diucapkan pada cerita, namun dalam respon identifikasi, mereka memiliki jawaban yang berbeda. $\mathrm{P}$ terlihat cukup mampu mengenali kalimat yang seharusnya tidak diucapkan, Sedangkan $\mathrm{Z}$ seringkali salah dalam mengidentifikasi kalimat yang seharusnya tidak diucapkan. Sebagai contoh: 
Tabel 5 Contoh Respon Faux Pas Stories Test

\begin{tabular}{|c|c|c|}
\hline \multicolumn{3}{|c|}{$\begin{array}{l}\text { Cerita } 2 \\
\text { Robi mulai masuk sekolah baru. Dia berkata pada teman barunya Andi, "Ibuku adalah penjaga } \\
\text { kantin di sekolah ini." Kemudian Cica datang dan berkata, "Aku benci penjaga kantin. Mereka } \\
\text { menyeramkan!" "Kamu mau ikut main kasti?" Andi bertanya pada Cica. "Nggak," kata Cica, } \\
\text { "Aku lagi nggak enak badan." }\end{array}$} \\
\hline Pertanyaan & Respon $\mathbf{P}$ & Respon $\mathbf{Z}$ \\
\hline $\begin{array}{l}\text { Pertanyaan Deteksi: } \\
\text { Adakah kata-kata yang tidak } \\
\text { tepat dalam cerita tadi? }\end{array}$ & Ada & Ada \\
\hline $\begin{array}{l}\text { Pertanyaan Identifikasi: } \\
\text { Perkataan apa yang seharusnya } \\
\text { tidak dikatakan? Kenapa? }\end{array}$ & $\begin{array}{l}\text { "Aku benci penjaga kantin. } \\
\text { Mereka menyeramkan!" } \\
\text { INQ: Karena si Cica mengejek } \\
\text { secara fisik ibunya Robi }\end{array}$ & $\begin{array}{l}\text { "Kamu mau main kasti?" } \\
\text { INQ: Nggak nyambung }\end{array}$ \\
\hline $\begin{array}{l}\text { Pertanyaan Komprehensi: } \\
\text { Apa pekerjaan ibu Robi? }\end{array}$ & Penjaga kantin & Penjaga kantin sekolah \\
\hline $\begin{array}{l}\text { Pertanyaan false-belief: } \\
\text { Apakah Cica tahu bahwa ibu } \\
\text { Robi adalah penjaga kantin? }\end{array}$ & Pasti tahu & Tahu \\
\hline
\end{tabular}

Melalui contoh respon di atas, dapat dilihat bahwa $\mathrm{P}$ dapat dengan tepat menunjukkan kalimat yang seharusnya tidak dikatakan dan mengungkapkan alasannya dengan benar. Sedangkan Z, gagal untuk mengidentifikasi kalimat mana yang seharusnya tidak diucapkan. Kesalahan yang dilakukan Z ini, dapat mengindikasikan bahwa $\mathrm{Z}$ kesulitan untuk memproses informasi yang penting dari cerita yang didapatkan. Hal ini karena faux pas berisi skenario yang kompleks, sehingga beberapa anak dengan ASD dapat mengalami kesulitan untuk memproses informasi yang penting (Gonzales-Gadea dalam Garcia-Molina, 2019).

Dari Tabel 5 juga dapat dilihat bahwa kedua subjek berhasil menjawab dengan benar pertanyaan komprehensi, hal ini berarti kedua subjek tidak memiliki masalah untuk memahami isi dari cerita yang disajikan. Sedangkan pada pertanyaan false-belief, kedua subjek melakukan kesalahan dalam menjawab. Seharusnya jawaban dari pertanyaan itu adalah tidak tahu, dengan melihat bahwa Cica datang terlambat dan bisa jadi dia tidak tahu bahwa ibu Robi adalah penjaga kantin yang sedang dibicarakannya. Hal ini menunjukkan bahwa kedua subjek gagal mengenali faux pas (kesalahan palsu) dalam cerita ini. 
Memahami faux pas berarti memahami status mental seseorang dimana pembicara tersebut memiliki belief yang berbeda, dia bisa jadi tidak tahu atau tidak ingat sesuatu (perilaku yang tidak bertendensi), dan mengapresiasi dampak emosional (biasanya negatif) dari komentar atau perilaku yang dilakukan kepada pendengar. Status mental yang terlibat dalam faux pas ini adalah niat, belief, dan emosi (Baron-Cohen dalam Garcia, 2019).

Hal ini mengakibatkan $\mathrm{P}$ dan $\mathrm{Z}$ kesulitan dalam memahami orang-orang di sekitarnya, terlihat dari perilaku $\mathrm{P}$ dan $\mathrm{Z}$ yang seringkali membicarakan hal yang mereka senangi tanpa memedulikan persepsi orang-orang di sekitarnya. Selain itu, $\mathrm{P}$ dan $\mathrm{Z}$ juga kesulitan untuk membedakan niat teman yang mengajak bercanda dan benar-benar mem-bully, sehingga mereka cenderung menjaga jarak dari teman-teman seusianya dan tidak memiliki teman dekat.

\section{Kemampuan Problem Solving}

Kemampuan problem solving yang dimiliki oleh remaja ASD diukur melalui dua alat ukur, yakni Problem Solving Questionnaire (Cote, 2011) dan Recognizing and Responding to a Problem Situation (Vlachou, 2016). Berikut adalah hasil dari masing-masing alat ukur yang dipakai:

\section{a. Problem Solving Questionnaire}

Tabel 6. Respon Problem Solving Questionnaire

\begin{tabular}{|c|c|c|c|}
\hline No & Pertanyaan & Respon P & Respon $\mathrm{Z}$ \\
\hline 1 & Apakah masalah itu? & $\begin{array}{l}\text { Sesuatu yang harus } \\
\text { diselesaikan secara baik. } \\
\text { Masalah dengan teman atau } \\
\text { pelajaran. }\end{array}$ & $\begin{array}{l}\text { Masalah, sering diganggu. } \\
\text { Suka main bola, ada yang } \\
\text { ngilokin terus marah yang } \\
\text { bikin suka berantem }\end{array}$ \\
\hline 2 & $\begin{array}{l}\text { Masalah apa yang kamu } \\
\text { punya baru-baru ini? }\end{array}$ & $\begin{array}{l}\text { P mampu menyebutkan } \\
\text { dengan detail masalah yang } \\
\text { dialaminya baru-baru ini }\end{array}$ & $\begin{array}{l}\mathrm{Z} \text { mampu menyebutkan } \\
\text { dengan detail masalah yang } \\
\text { dialaminya baru-baru ini }\end{array}$ \\
\hline 3 & $\begin{array}{l}\text { Apa yang telah kamu } \\
\text { lakukan untuk } \\
\text { menyelesaikan masalah } \\
\text { ini? }\end{array}$ & $\begin{array}{l}\text { P kurang mampu untuk } \\
\text { menyelesaikan permasalahan } \\
\text { sosial yang dihadapinya. Cara } \\
\text { penyelesaiannya cenderung } \\
\text { menggunakan teknik } \\
\text { menghindar (avoidance) }\end{array}$ & $\begin{array}{l}\mathrm{Z} \text { kurang mampu untuk } \\
\text { menyelesaikan permasalahan } \\
\text { sosial yang dihadapinya. Cara } \\
\text { penyelesaiannya cenderung } \\
\text { impulsif. }\end{array}$ \\
\hline 4 & $\begin{array}{l}\text { Apakah kamu dapat } \\
\text { menyelesaikannya sampai } \\
\text { selesai? }\end{array}$ & $\begin{array}{l}\text { P merasa bisa menyelesaikan } \\
\text { masalah jika minta tolong } \\
\text { pada figur otoritas }\end{array}$ & $\begin{array}{l}\mathrm{Z} \text { merasa bisa menyelesaikan } \\
\text { masalah jika minta tolong } \\
\text { pada figur otoritas }\end{array}$ \\
\hline 5 & $\begin{array}{l}\text { Kapan terakhir kali } \\
\text { kamupunya masalah? }\end{array}$ & $\begin{array}{l}\text { P dapat memperkirakan kapan } \\
\text { ia memiliki masalah yang } \\
\text { telah disebutkan sebelumnya }\end{array}$ & $\begin{array}{l}\text { Z dapat memperkirakan } \\
\text { kapan ia memiliki masalah } \\
\text { yang telah disebutkan } \\
\text { sebelumnya }\end{array}$ \\
\hline
\end{tabular}




\begin{tabular}{clll}
\hline No & \multicolumn{1}{c}{ Pertanyaan } & \multicolumn{1}{c}{ Respon P } & \multicolumn{1}{c}{ Respon Z } \\
\hline 6 & $\begin{array}{l}\text { Apa kamu meminta } \\
\text { bantuan untuk } \\
\text { menyelesaikannya? }\end{array}$ & $\begin{array}{l}\text { P seringkali meminta bantuan } \\
\text { kepada figur otoritas (guru) } \\
\text { ketika menghadapi masalah }\end{array}$ & $\begin{array}{l}\text { Z seringkali meminta bantuan } \\
\text { kepada figur otoritas (guru } \\
\text { atau orangtua) ketika } \\
\text { menghadapi masalah }\end{array}$ \\
\hline 7 & $\begin{array}{l}\text { Siapa yang kamu mintai } \\
\text { bantuan waktu kamu } \\
\text { punya masalah? }\end{array}$ & $\begin{array}{l}\text { P dapat menyebutkan kepada } \\
\text { siapa ia meminta bantuan }\end{array}$ & $\begin{array}{l}\text { Z dapat menyebutkan kepada } \\
\text { siapa ia meminta bantuan }\end{array}$ \\
\hline 8 & $\begin{array}{l}\text { Bantuan apa yang } \\
\text { diberikan orang lain untuk } \\
\text { menyelesaikan } \\
\text { masalahmu? }\end{array}$ & $\begin{array}{l}\text { P mampu untuk mengetahui } \\
\text { apakah bantuan orang lain } \\
\text { dapat benar-benar membantu } \\
\text { masalahnya atau tidak }\end{array}$ & $\begin{array}{l}\text { Z mampu untuk mengetahui } \\
\text { apakah bantuan orang lain } \\
\text { dapat benar-benar membantu } \\
\text { masalahnya atau tidak }\end{array}$ \\
\hline
\end{tabular}

\section{b. Recognizing and Responding to a Problem Situation}

Tabel 7. Skor RRPS

\begin{tabular}{|c|c|c|c|c|c|c|c|c|c|c|}
\hline \multirow{3}{*}{ Tahap } & \multicolumn{5}{|c|}{ Respon P } & \multicolumn{5}{|c|}{ Respon Z } \\
\hline & \multicolumn{5}{|c|}{ Skor Cerita* } & \multicolumn{5}{|c|}{ Skor Cerita* } \\
\hline & 1 & 2 & 3 & 4 & 5 & 1 & 2 & 3 & 4 & 5 \\
\hline $\begin{array}{c}\text { Pengenalan } \\
\text { masalah }\end{array}$ & 3 & 3 & 1 & 3 & 1 & 3 & 3 & 3 & 3 & 1 \\
\hline $\begin{array}{c}\text { Definisi dan } \\
\text { Formula Masalah }\end{array}$ & 3 & 3 & 1 & 3 & 1 & 3 & 3 & 3 & 3 & 1 \\
\hline Solusi & 3 & 2 & 1 & 3 & 1 & 3 & 2 & 3 & 2 & 1 \\
\hline Alternatif Solusi & 1 & 3 & 1 & 1 & 1 & 3 & 2 & 3 & 3 & 1 \\
\hline Keputusan & 3 & 2 & 1 & 3 & 1 & 3 & 2 & 3 & 2 & 1 \\
\hline $\begin{array}{l}\text { Justifikasi } \\
\text { Keputusan }\end{array}$ & 2 & 2 & 1 & 2 & 1 & 2 & 1 & 3 & 3 & 1 \\
\hline
\end{tabular}

Kemampuan problem solving atau penyelesaian masalah sehari-hari yang dimiliki oleh $\mathrm{P}$ dan $\mathrm{Z}$ cenderung menunjukkan pola penyelesaian masalah yang disfungsional. Pola penyelesaian masalah disfungsional terbagi menjadi dua yaitu impulsif dan avoidance (menghindar). Pola penyelesaian masalah impulsif ditandai dengan adanya percobaan aktif untuk menyelesaikan masalah namun sifatnya dangkal, terburu-buru, ceroboh, dan kurang lengkap (D’Zurilla, 2004), hal ini dapat terlihat dari perilaku $\mathrm{Z}$ dalam menyelesaikan masalah sosial yang dihadapinya sehari-hari, ia cenderung melakukan pendekatan yang banyak namun tidak efektif saat mencari alat tulis yang diambil oleh temannya, selain itu juga saat menghadapi ejekan temannya, ia cenderung berteriak-teriak dan lari masuk ke dalam rumah. Sedangkan pola penyelesaian masalah avoidance digambarkan dengan perilaku prokrastinasi, pasif atau tidak bertindak, dan ketergantungan (D’Zurilla, 2004), karakteristik ini lekat dengan pola penyelesaian masalah yang 
dipraktikkan oleh P dimana ia cenderung untuk menghindar dari masalah sosial yang dihadapi, pergi dari sumber masalah dan tidak melakukan apa-apa, penundaan menyelesaikan masalah ketika botolnya hilang. $\mathrm{P}$ dan $\mathrm{Z}$ juga seringkali masih meminta bantuan pada orang lain untuk menyelesaikan masalahnya (ketergantungan), walaupun pada beberapa kasus memang butuh bantuan dan mereka dapat meminta tolong kepada orang yang tepat.

Sedangkan penyelesaian masalah dalam kasus normatif, mereka disajikan satu cerita dan diajukan pertanyaan satu per satu unutk dijawab (RRPS), P dan Z cukup dapat menunjukkan pola penyelesaian masalah yang konstruktif. Penyelesaian masalah yang konstruktif ditunjukkan dengan solusi yang rasional, penuh pertimbangan, dan efektif (D'Zurilla, 2004). P dan Z mampu menjawab solusi yang memberikan efek positif bagi kedua belah pihak yang sedang bermasalah (win-win solution). Sayangnya, baik $\mathrm{P}$ maupun $\mathrm{Z}$ masih kurang kreatif dalam menemukan alternatif solusi dari masalah yang ada. Mereka cenderung mengungkapkan satu atau dua solusi pada tiap masalah yang muncul, seharusnya mereka dapat mengungkapkan minimal dua solusi dari tiap permasalahan (D’Zurilla, 2004).

Kemampuan identifikasi masalah pada tes RRPS, keduanya menunjukkan performa yang cukup baik. Hanya saja, dalam cerita kontrol yang seharusnya tidak ditemukan masalah, $\mathrm{P}$ justru mengatakan terdapat masalah. Hal ini dikarenakan $\mathrm{P}$ memiliki persepsi yang berbeda dan pemahaman bahasa yang kurang fleksibel. Sebagai contoh, pada cerita ke-tiga dimana Putra dan Andi bermain bola bersama, diartikan oleh P bahwa keduanya menendang bola secara bersama-sama, harusnya bergantian. Pemaknaan kata 'bersama' inilah yang membuat $\mathrm{P}$ melihat ada masalah dalam cerita tersebut. Akibatnya dalam kehidupan sosial, $\mathrm{P}$ akan menemukan kesulitan saat orang lain menggunakan kata-kata yang bisa menggambarkan berbagai macam arti atau konotasi, sehingga dapat menimbulkan kesalahpahaman di antara keduanya.

4. Peran orangtua dalam melatih keterampilan sosial pada remaja ASD

Keterampilan sosial pada remaja ASD merupakan tantangan bagi orangorang di sekitarnya untuk dapat membantu mereka agar lebih dapat berfungsi dan 
diterima di masyarakat. Hal ini tentunya membutuhkan peran orangtua yang sangat besar. Seperti yang diungkapkan oleh Laugeson (dalam Karst, 2014) bahwa peran orangtua sebagai social coaching menjadi penguat dan mampu membuat keterampilan sosial yang dimiliki oleh individu ASD bertahan lebih lama.

Besarnya peran yang bisa diberikan orangtua dalam melatih keterampilan sosial pada remaja ASD menunjukkan bahwa orangtua perlu memiliki pengetahuan dan kemampuan untuk dapat mendampingi anak-anak mereka. Dari hasil asesmen yang telah dilakukan, ditemukan bahwa pemahaman keterampilan sosial dari orangtua masih sangat terbatas pada cara-cara menjalin pertemanan, berkenalan, cara berbicara dan bergaul yang baik, serta bagaimana caranya untuk menyudahi pembicaraan. Akibatnya, langkah yang ditempuh ibu $\mathrm{Z}$ untuk meningkatkan keterampilan sosial pada remaja ASD adalah dengan mendorong Z untuk lebih aktif dalam kegiatan sosial di lingkungan rumah maupun sekolah, tanpa didampingi. Sedangkan ibu $\mathrm{P}$ memiliki anggapan bahwa keterampilan sosial merupakan potensi bawaan anak, sehingga ibu tidak terlalu mendorong $\mathrm{P}$ untuk dapat lebih bersosialisasi dengan teman sebayanya.

Pengetahuan ibu tentang keterampilan sosial ini cukup mewakili dari definisi keterampilan sosial yang diungkapkan oleh Gresham (dalam Daraee, 2016) yakni sekumpulan perilaku belajar yang memberikan individu kemampuan untuk memiliki hubungan timbal balik dengan orang lain, di antaranya adalah kerjasama, kolaborasi dengan orang lain, saling menolong, menginisiasi sebuah hubungan, cara meminta tolong, dan cara mengapresiasi orang lain. Sayangnya, contoh-contoh perilaku yang diungkapkan oleh Gresham tadi lebih cocok jika disetarakan dengan anak dengan perkembangan normal karena anak atau remaja dengan ASD, memiliki tantangan dan hambatan tersendiri dalam keterampilan sosialnya.

Keterampilan sosial pada individu dengan ASD banyak memiliki tantangan pada proses internalnya (Solomon, 2004). Proses internal ini meliputi cara menginterpretasi pesan sosial, serta mengenali dan mengelola emosi serta reaksi (Patrick, 2008). Solomon (2004) menggarisbawahi bahwa dalam proses 
internal individu dengan ASD, terdapat tiga aspek utama yakni kesadaran dan pemahaman emosi, theory of mind, dan problem solving. Dari hasil asesmen yang dilakukan, para ibu belum menyadari bahwa ada tiga aspek penting yang perlu diperhatikan untuk meningkatkan keterampilan sosial pada remaja ASD. Hal ini tergambar dari self-evaluation yang telah dilakukan oleh ibu, dimana mereka terlihat kurang terstruktur dalam mengajarkan dan melatih ketiga aspek keterampilan sosial tersebut. Masih banyak sub-aspek yang belum pernah disentuh oleh ibu untuk diajarkan kepada remaja ASD. Selain itu dalam penyampaian, kurang adanya kontinuitas dan intensitas pengajaran dalam jangka waktu yang panjang. Ibu cenderung memberikan stimulasi dengan ceramah, menasehati dan kurang memaksimalkan alat peraga yang ada di sekitarnya, seperti televisi, handphone, buku, dan lainnya sebagai media untuk melatih keterampilan sosial pada remaja ASD. Padahal individu dengan ASD membutuhkan cara pengajaran yang terstruktur, terpola, terprogram, konsisten, dan berkelanjutan (Sukinah, 2010). Individu dengan ASD juga banyak menggunakan gaya belajar kinestetik dan visual (Roberts dalam Colorosa, 2014; Hogdgon, 1995) sehingga mereka akan lebih mudah belajar dengan menggunakan berbagai macam media.

Menurut Solomon (2004), cara untuk mengajarkan kesadaran dan pemahaman emosi kepada individu ASD adalah dengan cara memberikan pengenalan dan pemahaman terhadap berbagai bentuk emosi seperti senang, sedih, marah, takut, jijik, dan kaget. Langkah selanjutnya adalah bagaimana menangkap dan mengekspresikan bahasa tubuh (ekspresi wajah, postur badan, dan nada suara) yang diajarkan melalui modelling dan role play. Dari asesmen yang telah dilakukan, terlihat ibu $\mathrm{P}$ tidak pernah mengenalkan ataupun memberikan pemahaman berbagai bentuk emosi dan mengajarkan anak untuk melihat petunjuk-petunjuk emosi yang didapat dari bahasa tubuh. Ibu P cenderung untuk langsung memberikan kesimpulan bahwa si A tidak suka pada $\mathrm{P}$, maka dari itu jangan dekat-dekat, dan lain sebagainya. Sedangkan ibu Z, pernah mengenalkan dan meminta $\mathrm{Z}$ untuk memperhatikan ekspresi wajah orang lain pada saat $\mathrm{Z}$ masih 
kecil. Akibatnya, kemampuan $\mathrm{P}$ dan $\mathrm{Z}$ untuk dapat mengenal ekspresi wajah dan mengekspresikannya juga cenderung kurang.

Dalam melatih theory of mind, Ozonoff (1995) melakukan beberapa tahapan yakni dengan mengajarkan first order perspective taking, bagaimana seseorang bisa mengetahui sesuatu tapi tidak dengan orang lainnya, menekankan bahwa persepsi mempengaruhi pengetahuan bahwa apa yang dilihat atau didengar oleh orang akan menentukan tentang apa yang ia ketahui. Selanjutnya dijarakan second order perspective taking, yaitu memprediksikan apa yang seseorang pikirkan mengenai apa yang dipikirkan orang lain. Kedua hal ini dapat diajarkan melalui cara role play. Kedua hal tersebut, akan lebih lengkap jika individu dengan ASD juga diajarkan untuk memahami status mental orang lain (Hutchins, 2008). Dari beberapa tahap yang dikemukakan oleh Ozonoff dan Hutchins, terlihat bahwa ibu dari $\mathrm{P}$ maupun $\mathrm{Z}$ tidak terstruktur dalam mengajarkan kemampuan theory of mind ini. Ibu cenderung untuk langsung mengambil contoh masalah sehari-hari dan memberikan pemahaman bahwa masing-masing orang memiliki niat, perasaan, nilai yang berbeda dari orang lain. $\mathrm{P}$ dan $\mathrm{Z}$ tidak ditunjukkan kenapa perbedaan itu dapat terjadi, bagaimana cara memperkirakan pikiran orang lain, dan status mental orang lain. Oleh karenanya, $\mathrm{P}$ dan $\mathrm{Z}$ masih banyak mengalami hambatan dan tantangan dalam menjalin hubungan sosial dengan teman sebayanya. Mereka kesulitan untuk memahami apakah temannya memiliki minat yang sama dengannya, apakah temannya hanya bercanda biasa atau mengejek, dan lain sebagainya.

Sedangkan untuk melatih aspek problem solving, Yakubova (2017) menerapkan langkah penyelesaian masalah yang diutarakan oleh D'Zurilla dan Goldfried dalam bentuk cue sheet sehingga dapat menstimulasi individu dengan ASD agar tetap melewati tahap demi tahap saat melakukan masalah yang ditemuinya. Langkah penyelesaian masalah tersebut adalah (a) mengidentifikasi masalah; (b) mengidentifikasi minimal dua solusi; (c) mengevaluasi tiap solusi, menyatakan bagaimana tiap solusi akan bekerja; (d) memilih solusi terbaik; (e) mengimplementasikan solusi; (f) menentukan apakah masalah telah selesai, jika belum individu mengimplementasikan solusi terbaik selanjutnya; (g) slef- 
reinforces. Jika dilihat dari hasil asesmen yang dilakukan, ibu $\mathrm{P}$ maupun $\mathrm{Z}$ sama sekali tidak mencerminkan langkah-langkah tersebut. Mereka cenderung untuk langsung memberikan saran atau nasehat tentang apa yang sebaiknya dilakukan oleh $\mathrm{P}$ ataupun $\mathrm{Z}$. Mereka tidak memberikan kesempatan bagi $\mathrm{P}$ ataupun $\mathrm{Z}$ untuk menyelesaikan masalahnya sendiri.

\section{Kesimpulan dan Saran}

Berdasarkan hasil penelitian yang telah dipaparkan, dapat dilihat bahwa peran orangtua dalam melatih keterampilan sosial pada remaja dengan ASD masih sudah ada upaya positif yang dilakukan tapi masih dapat dioptimalkan. Keterampilan remaja dengan ASD (P dan Z) masih belum optimal dan cenderung menjaga jarak dengan teman sebayanya. Kemampuan mereka dalam tiap aspek pun masih tergolong kurang, walaupun pada aspek problem solving, secara normatif mereka cukup dapat menunjukkan performa yang baik. Upaya yang dilakukan kedua ibu dari remaja dengan ASD tersebut menggunakan pendekatan kepada remaja dengan perkembangan normal, dan kurang memperhatikan kekhususan yang dimiliki oleh remaja ASD. Pada akhirnya, keterampilan sosial remaja ASD tidak meningkat dan ibu merasa tidak mampu untuk membantu meningkatkan keterampilan sosial anak-anak mereka. Saran yang diberikan peneliti kepada orangtua dalam penelitian ini adalah:

1. Orangtua dapat meningkatkan pengetahuan mengenai kesadaran dan pemahaman emosi, theory of mind, dan problem solving untuk meningkatkan keterampilan sosial yang dimiliki oleh remaja ASD.

2. Orangtua meningkatkan pengetahuan dan keterampilan untuk melatih kesadaran dan pemahaman emosi, theory of mind, dan problem solving agar dapat meningkatkan keterampilan sosial pada remaja ASD.

3. Orangtua menggunakan berbagai macam media yang tepat dan sesuai dengan gaya belajar ASD untuk dapat mengajarkan keterampilan sosial pada remaja dengan ASD. 


\section{DAFTAR PUSTAKA}

American Psychiatric Association. (2000). Diagnostic and Statistical manual of Mental Disorders IV Text Revision. Washington DC: American Psychiatric Association Press.

Begeer, S., Gevers, C., Clifford, P., Verhoeve, M., Kat, K., Hoddenbach, E., \& Boer, F. (2011). Theory of mind training in children with autism: A randomized controlled trial. Journal of Autism and Developmental Disorder, 41: 997-1006.

Berggren, S. (2017). Emotion Recognition and Expression in Autism Spectrum Disorder: Significance, Complexity, and Effect of Training. Stockholm: Karolinska Institutet.

Colorosa, S.R., \& Makela. C.J. (2014). Integrative Literature Review: Styles of Learning for Autism Spectrum Disorders and Human Resources Development: Informing Performance Management. International Journal of Business and Social Science. 5(13): 1-12.

Cote, Debra L. (2011). Implementing a problem-solving intervention with students with mild to moderate disabilities. Intervention in School and Clinic, 46(5): 259-265. DOI: 10.1177/1053451210395387.

D’Zurilla, T. J., Nezu, A. M., \& Maydeu-Olivares, A. (2004). Social problem solving: theory and assessment. In E. C. Chang, T. J. D'Zurilla and L. J. Sanna (eds), Social Problem Solving: Theory, Research, and Training, pp. 11-27. Washington, DC: American Psychological Association.

Daraee, M., Salehi, K., \& Fakhr, M. (2016). Comparison of social skills between students in ordinary and talented schools. The European Proceedings of Social and Behavioral Sciences. DOI: 10.15405/epsbs.2016.11.52.

Garcia-Molina, I., \& Clemente-Estevan, R.A. (2019). Autism and faux pas, influences of presentation modality and working memory. The Spanish Journal of Psychology, 22: E13. DOI: 10.1017/sjp.2019.13.

Gutstein, S. R., \& Whitney, T. (2002). Asperger Syndrome and the development of Social Competence. Focus on Autism and Other Developmental Disabilities, 17(3), 161-171.

Hogdgon, L.A. (1995). Visual Strategies for Improving Communication-Practical Supports for School and Home. Michigan: Quick Roberts Publishing. 
Hutchings, T. L., \& Prelock, P. A. (2008). Supporting theory of mind development: considerations and recommendations for professionals providing services to individuals with autism spectrum disorder. Topics in Language Disorders. 28(4): 340-364.

Karst, J.S. et al. (2014). Parent and Family Outcomes of PEERS: A Social Skills Intervention for Adolescents with Autism Spectrum Disorder. Journal Autism Development Disorder. DOI 10.1007/s10803-014-2231-6.

Lee, T.M., Ip, A. K., Wang, K., Xi, C. H., Hu, P. P., Mak, H. K., . . Chan, C. C. (2010). Faux pas deficits in people with medial frontal lesions as related to impaired understanding of a speaker's mental state. Neuropsychologia, 48(6):1670-6. DOI: 10.1016/j.neuropsychologia.2010.02.012.

Little, S.G., Swangler, John., \& Little, A.A. (2017). Handbook of Social Behavior and Skills in Children: Defining Social Skills. Springer International Publishing AG.

Lundqvist, D., Flykt, A., \& Öhman, A. (1998). The Karolinska Directed Emotional Faces - KDEF, CD ROM from Department of Clinical Neuroscience, Psychology section, Karolinska Institutet, ISBN 91-6307164-9.

Olsson, N.C. et al. (2017). Social Skills Training for Children and Adolescents with Autism Spectrum Disorder: A Randomized Controlled Trial. Journal of the American Academy of Child \& Adolescent Psychiatry. 56(7): 585-592.

Ozonoff, S., \& Mille, J. N. (1995). Teaching theory of mind: a new approach to social skills training for individuals with autism. Journal of Autism and Developmental Disorders. 25(4): 415-433.

Patrick, Nancy J. (2008). Social Skills for Teenagers and Adults with Asperger Syndrome. Philadelphia: Jessica Kingsley Publishers.

Solomon, Marjorie., Jones, B.L.G., \& Anders, T.F. (2004). A Social Adjustment Enhancement Intervention for High Functioning Autism, Asperger's Syndrome, and Pervasive Developmental Disorder NOS. Journal of Autism and Developmental Disorder. 34(6): 649-668.

Sukinah. (2010). Manajemen strategi implementasi pendidikan inklusi. Jurnal Pendidikan Khusus UNY. 7(2):46.

Sukmadinata, N.S. (2011). Metode Penelitian Pendidikan. Bandung: Remaja Rosadakarya. 
Tanaka, J.W., \& Sung, Andrew. (2016). The "Eye Avoidance" Hypothesis of Autism Face Processing. Journal of Autism and Developmental Disorder. 46(5): 1538-1552.

Vlachou, Anastasia., \& Stavroussi, Panayiota. (2016). Promoting social inclusion: a structured intervention for enhancing interpersonal problem-solving skills in children with mild intellectual disabilities. Support for Learning, 31(1): 27-45. DOI: 10.1111/1467-9604.12112.

Weiss, M. J., \& Harris, S. L. (2001). Teaching Social Skills to People with Autism. Behavior Modification, 25: 785-802.

Wegrzyn, M., Vogt, M., Kireclioglu B., Schneider, J., \& Kissler, J. (2017). Mapping the emotional face: How individual face parts contribute to successful emotion recognition. PloS ONE 12(5): e0177239. DOI 10.1371/journal.pone.0177239.

Westra, Evan., \& Carruthers, Peter. (2018). Encyclopedia of Evolutionary Psychological Science: Theory of Mind. Springer International Publishing. DOI: 10.1007/978-3-319-16999-6_2376-1.

White, S.W., Keonig, Kathleen., \& Scahill, Lawrence. (2007). Social Skills Development in Children with Autism Spectrum Disorders: A Review of the Intervention Research. Journal Autism Development Disorder, 37: 18581868.

Yakubova, G., \& Taber-Doughty, T.(2017). Improving problem-solving performance of students with autism spectrusm disorders. Focus on Autism and Other Developmental Disabilities. 32(1): 3-17. 